\title{
Effects of physical processes on structure and transport of thin zooplankton layers in the coastal ocean
}

\author{
Margaret A. McManus ${ }^{1, *}$, Olivia M. Cheriton ${ }^{2}$, Patrick T. Drake ${ }^{3}$, D. V. Holliday ${ }^{4}$, \\ Curt D. Storlazzi ${ }^{5}$, Percy L. Donaghay ${ }^{6}$, Charles F. Greenlaw ${ }^{4}$ \\ ${ }^{1}$ University of Hawaii, Department of Oceanography, Honolulu, Hawaii 96822, USA \\ ${ }^{2}$ University of California Santa Cruz, Ocean Sciences Department, Santa Cruz, California 95064, USA \\ ${ }^{3}$ University of California Santa Cruz, Long Marine Laboratory, Santa Cruz, California 95060, USA \\ ${ }^{4}$ BAE SYSTEMS, 4669 Murphy Canyon Road, San Diego, California 92123, USA \\ ${ }^{5}$ US Geological Survey, Pacific Science Center, Santa Cruz, California 95060, USA \\ ${ }^{6}$ University of Rhode Island, Graduate School of Oceanography, Narragansett, Rhode Island 02882, USA
}

\begin{abstract}
Thin layers of plankton are recurrent features in a variety of coastal systems. These layers range in thickness from a few centimeters to a few meters. They can extend horizontally for kilometers and have been observed to persist for days. Densities of organisms found within thin layers are far greater than those above or below the layer, and as a result, thin layers may play an important role in the marine ecosystem. The paramount objective of this study was to understand the physical processes that govern the dynamics of thin layers of zooplankton in the coastal ocean. We deployed instruments to measure physical processes and zooplankton distribution in northern Monterey Bay; during an $11 \mathrm{~d}$ period of persistent upwelling-favorable winds, 7 thin zooplankton layers were observed. These zooplankton layers persisted throughout daylight hours, but were observed to dissipate during evening hours. These layers had an average vertical thickness of $1.01 \mathrm{~m}$. No layers were found in regions where the Richardson number was $<0.25$. In general, when the Richardson number is $<0.25$ the water column is unstable, and incapable of supporting thin layers. Thin zooplankton layers were also located in regions of reduced flow. In addition, our observations show that the vertical depth distribution of thin zooplankton layers is modulated by high-frequency internal waves, with periods of 18 to $20 \mathrm{~min}$. Results from this study clearly show an association between physical structure, physical processes and the presence of thin zooplankton layers in Monterey Bay. With this new understanding we may identify other coastal regions that have a high probability of supporting thin layers.
\end{abstract}

KEY WORDS: Thin layer $\cdot$ Physical processes $\cdot$ Transport $\cdot$ Zooplankton $\cdot$ Coastal circulation Resale or republication not permitted without written consent of the publisher

\section{INTRODUCTION}

The distribution of marine plankton varies both horizontally and vertically across a continuum of time and space scales in the ocean (Cassie 1963, Wiebe \& Holland 1968, Haury et al. 1978). Often, high plankton biomass is found at physical discontinuities, such as fronts, or associated with episodic physical or environmental events, such as intermittent upwelling (Paffen- höfer et al. 1987, Marine Zooplankton Colloquium 2 2001). Recent advances in instrumentation and sampling techniques (Donaghay et al. 1992, Cowles \& Desiderio 1993, Hanson \& Donaghay 1998, Holliday et al. 1998) have revealed vertically thin, layered structures comprised of marine plankton. These 'thin layers' range in vertical extent from a few centimeters to a few meters, may extend horizontally for kilometers and may persist for days (Rines et al. 2002). These layers 
are characterized by in-layer plankton densities that can be far greater than the densities just above or below the structure. Thin layers have generally been studied using high-resolution optical and acoustical sensors. Direct biological sampling of these structures indicates that they can be formed by intense aggregations of phytoplankton, zooplankton, marine snow, viruses and bacteria (Donaghay et al. 1992, Johnson et al. 1995, Alldredge et al. 2002, Rines et al. 2002, McManus et al. 2003, G. Steward pers. comm.). Two long-term studies, one in 1996 and one in 1998, have been undertaken in a small fjord in the Pacific Northwest (Pacific NW). Dekshenieks et al. (2001), Alldredge et al. (2002) and Rines et al. (2002) describe results from the 1996 study, while McManus et al. (2003) describes results from the 1998 study. For the purposes of this publication, both of these studies will be referred to as the Pacific NW study. Results from the Pacific NW study revealed strong statistical relationships between thin phytoplankton layers and physical structure in the water column: $62 \%$ of thin layers of phytoplankton were located near the base of the pycnocline, $9 \%$ were in and above the primary pycnocline, $14 \%$ were associated with small density features below the pycnocline, and the remaining $15 \%$ occurred throughout the water column when the pycnocline was not well-defined (Dekshenieks et al. 2001). Thin acoustical scattering layers have been detected at both the base of the primary pycnocline and at subtle gradients in vertical thermal microstructure throughout the water column. These acoustical scattering layers have been associated with thin vertical distributions of zooplankton (Holliday \& Pieper 1980). Zooplankton in the Pacific NW study were also distributed in thin layer structures. Although the thin zooplankton layers were often associated with thin phytoplankton layers (McManus et al. 2003), at certain times thin zooplankton layers were displaced vertically from the phytoplankton layers (Holliday et al. 2003). This reinforces prior suggestions that multiple mechanisms can control the formation and depth distribution of thin layers of zooplankton (Donaghay \& Osborn 1997).

Over the last few years, we surveyed multiple coastal ocean sites around the continental US for the presence of thin layers. For several weeks at each site, between 15 and $30 \mathrm{~m}$ of the overlying water column was monitored for the presence of thin acoustical scattering layers. Specifically, we were interested in thin acoustical scattering layers that we could, by virtue of the characteristics of their acoustic volume-scattering spectra, associate with zooplankton. The primary objectives for surveying these sites varied, and as a result our ability to collect direct samples of organisms from the layer structures was limited. Data were collected at the following locations: Monterey Bay, California; East and West Sounds on Orcas Island in northern Puget Sound, Washington; 2 sites near Goleta Point, west of Santa Barbara, California; a site near Rincon Island, east of Santa Barbara, California; a site near Cape Perpetua, Oregon; and a location near West Destin, Florida. Data were also collected from shallow coastal sites near Oceanside, California and in Charleston Harbor, South Carolina. Thin zooplankton layers were observed at all these locations. Of the coastal sites monitored, Monterey Bay and East Sound had the most intense and the most persistent thin layers.

While we have documented that thin zooplankton layers are prevalent at multiple coastal ocean sites around the continental US, rigorous comparisons of thin zooplankton layer distribution and physical structure had not been made before this paper, whose purpose is to provide a description of thin zooplankton layers and the concurrent physical conditions under which these layers are observed. We also investigated the role that thin layers play in the transport and retention of marine plankton in coastal systems. Monterey Bay was chosen as the focus of the study because of the intensity and persistence of the thin zooplankton layers observed there during our surveys of coastal sites around the continental US.

Over the past $20 \mathrm{yr}$, a number of studies investigating the hydrography of Monterey Bay and its adjacent shelf have been conducted (Strub et al. 1987, Breaker \& Broenkow 1994, Paduan \& Rosenfeld 1996, Storlazzi et al. 2003, Drake et al. 2005). Remotely sensed and in situ data from these studies have provided a picture of the surface and internal circulation patterns. The flows in Monterey Bay can be characterized by 2 regimes: upwelling and relaxation from upwelling. The upwelling regime is characterized by northwesterly winds produced by offshore regions of high pressure. These northwesterly winds drive intense periods of upwelling at Point Año Nuevo, 20 nautical miles north of Monterey Bay (Fig. 1). This upwelling center produces a band of cold, nutrient-rich water that often crosses the entrance of Monterey Bay. During this time, the interior of the bay is characterized by a cyclonic gyre, formed as a dynamic response to active upwelling. This warm, re-circulating gyre is highly stratified and has a calculated residence time of 8 to 12 d (Graham \& Largier 1997). There are periods during which winds decrease in intensity or reverse direction, termed 'relaxation from upwelling events'. As the winds relax, the warm-water mass that is kept offshore by wind-driven Ekman transport during upwelling periods is advected onshore, the entire water column warms by 2 to $5^{\circ} \mathrm{C}$ and stratification temporarily breaks down (Storlazzi et al. 2003).

The following section describes instruments deployed to measure zooplankton distribution and physi- 


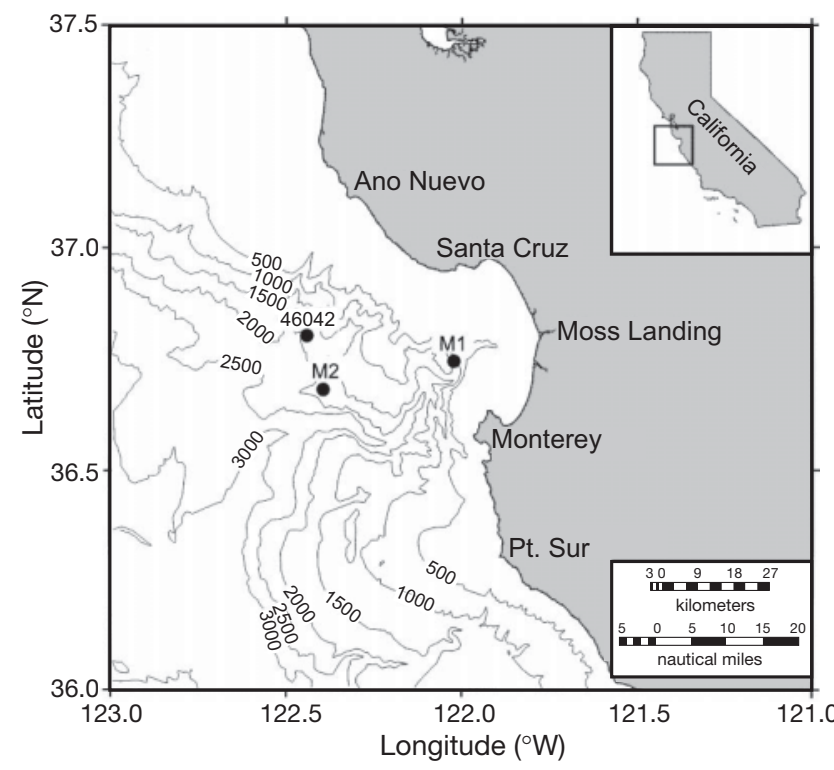

Fig. 1. Location and bathymetry of Monterey Bay and adjacent shelf. 46042: National Data Buoy Center's (NDBC) Monterey Buoy \#46042. M1 and M2: oceanographic moorings maintained by Monterey Bay Aquarium Research Institute (MBARI). Bathymetric contours in $500 \mathrm{~m}$. Reprinted with permission of Kudela \& Chavez (2000)

cal processes in northern Monterey Bay. This is followed by a comparison of thin zooplankton layers, physical structure and circulation patterns. We close with a general discussion of the role of thin zooplankton layers in the transport and retention of marine plankton in coastal systems.

\section{MATERIALS AND METHODS}

Study area. Monterey Bay is located on the central California coast between 36.5 and $37^{\circ} \mathrm{N}$. The bay is an open embayment, measuring roughly $37 \mathrm{~km}$ along its $\mathrm{N}-\mathrm{S}$ axis (i.e. across its mouth) and $19 \mathrm{~km}$ along its E-W axis (Breaker \& Broenkow 1994). The Monterey Submarine Canyon, which runs along the E-W axis, divides the bay into northern and southern regions (Fig. 1).

Sampling overview. Instruments used to measure zooplankton distribution and physical processes were deployed in northern Monterey Bay between 6 August and 9 September 2002. Data from these instruments were used in conjunction with offshore wind measurements in order to investigate the effect of local and regional circulation on zooplankton distribution in this region. Data presented in this paper are from an $11 \mathrm{~d}$ period (midnight on 17 August to midnight on 28 August 2002). This time frame was chosen because of the persistent upwelling-favorable winds during that period.
Zooplankton distribution. We deployed 1 Tracor Acoustical Profiling Sensor (TAPS-6, BAE Systems) in the alongshore array at Site A4 (Fig. 2). A $180 \mathrm{~kg}$ bottom-mounted frame was used to position the TAPS in an upward looking mode at a depth of $20 \mathrm{~m}$. The TAPS measured acoustical volume scattering strengths at 6 frequencies (between 265 and $3000 \mathrm{kHz}$ ) at $1 \mathrm{~min}$ intervals, with a vertical resolution of $0.125 \mathrm{~m}$. Every hour, data from the TAPS were telemetered to a receiving station on shore.

Zooplankton layers were identified and traced using a time depth visualization of volume scattering strength. The acoustic time series was rendered in $4 \mathrm{~h}$ intervals and, using Matlab's 'ginput' function, spatially
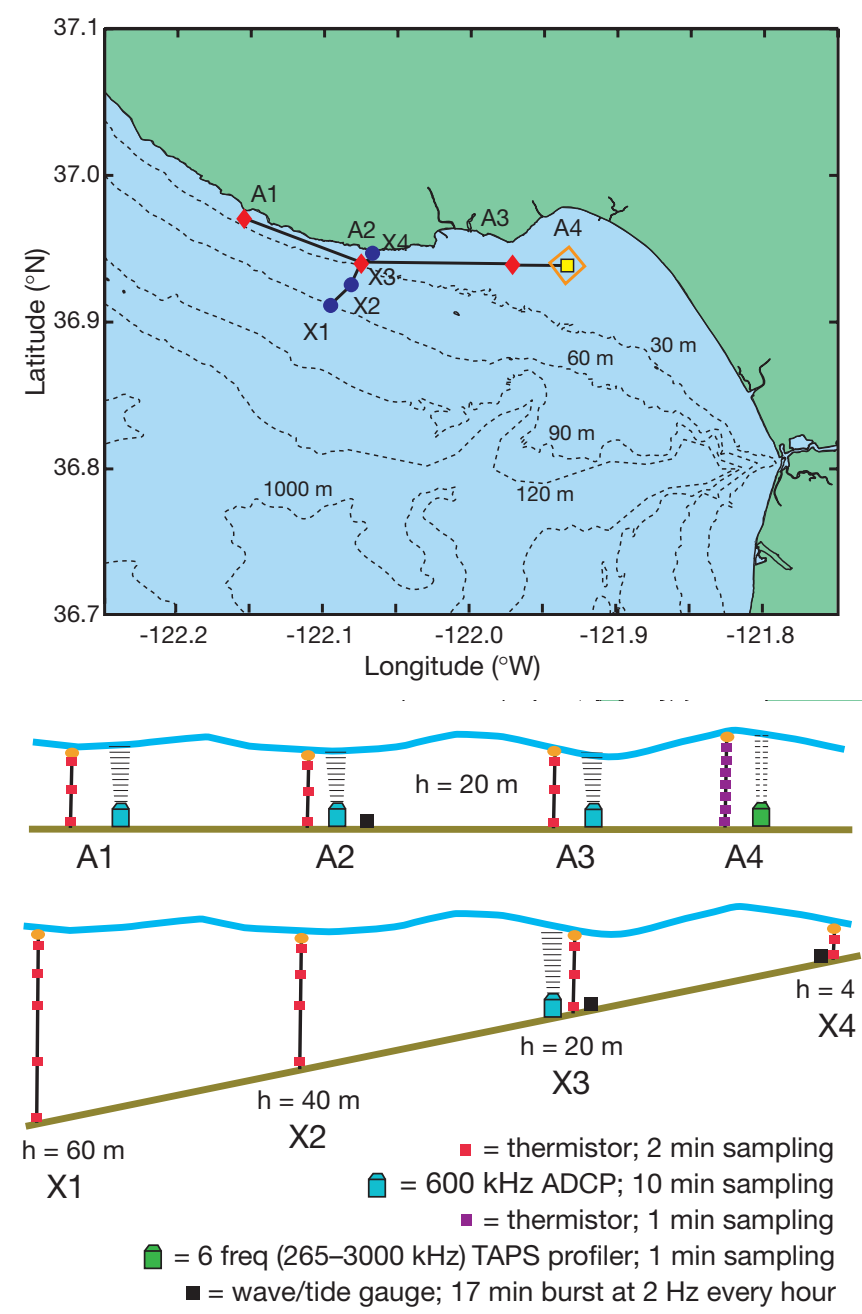

Fig. 2. Instrument deployment locations in northern Monterey Bay. Site A1 (20 m): thermistor chain and $600 \mathrm{kHz}$ ADCP; Site A2/X3 (20 m): thermistor chain, $600 \mathrm{kHz}$ ADCP, wave and tide gauge; Site A3 $(20 \mathrm{~m})$ : thermistor chain and $600 \mathrm{kHz}$ ADCP; Site A4 (20 m): thermistor chain, Tracor Acoustical Profiling System (TAPS) and $1000 \mathrm{kHz}$ ADCP; Site X1 (60 m): thermistor chain; Site X2 (40 m): thermistor chain; Site X4 $(4 \mathrm{~m}$ ): thermistor chain, wave and tide gauge (see Table 1 for depth of thermistors) 
and temporally coherent thin vertical structures (defined by high scattering levels relative to those in the surrounding water column) were manually digitized. Each layer trace resulted in a time and depth vector pair, which were then concatenated to create a complete record of the time and depth history of thin layers for the $11 \mathrm{~d}$ study period. The average thickness of each zooplankton layer was determined visually using the time depth visualization of scattering strength. For each layer, 4 thicknesses at different points in time were measured and averaged. While this paper discusses observations made of thin layers of zooplankton, previous studies have examined thin layers of phytoplankton and determined the thickness of phytoplankton layers by inspecting vertical optical profiles and measuring the thickness where the optical signal was at half maximum intensity (Dekshenieks et al. 2001).

Wave and tide gauge. We deployed 2 NIWA 'Dobie' wave and tide gauges, 1 located at Alongshore Site A2/X3 in $20 \mathrm{~m}$ of water, and 1 at Cross-shore Site X4 in $\sim 4 \mathrm{~m}$ of water. These instruments employ a Druck PMP 4000 Series pressure sensor with $0.8 \mathrm{~cm}$ accuracy. They registered a $512 \mathrm{~s}$ burst at $2 \mathrm{~Hz}$ (1024 points) on every full hour to measure waves and tides. Significant wave heights and dominant periods were computed spectrally using a 256 s Hanning-windowed autospectrum with $50 \%$ overlap (SuperDUCK method) which resolved waves with periods between 3 and $128 \mathrm{~s}$. Tides were computed as the mean water depth over the pressure sensor during each burst.

Temperature. Time series of water temperature were collected using Onset XTI temperature loggers on thermistor chains. The self-contained loggers have an accuracy of $0.2^{\circ} \mathrm{C}\left(0.4^{\circ} \mathrm{F}\right)$ and a response time of $15 \mathrm{~s}$. Measurements were obtained every $2 \mathrm{~min}$. We deployed 4 thermistor chains along the $20 \mathrm{~m}$ isobath, in an E-W configuration at: Sand Hill Bluff (Site A1), Long Marine Laboratory (Site A2), Soquel Point (Site A3) and Rio Del Mar (Site A4); 3 additional thermistor chains were deployed cross-shore at depths of $60 \mathrm{~m}$ (Site X1), $40 \mathrm{~m}$ (Site X2), and $4 \mathrm{~m}$ (Site X4). The $20 \mathrm{~m}$ thermistor chain at the Long Marine Laboratory (Sites A2, X3) was the focal point for this array (Fig. 2). The deployment depths of the temperature loggers are given in Table 1.

Individual isotherms were calculated by first creating a matrix of the temperature data and then vertically interpolating across the matrix values using $0.2 \mathrm{~m}$ depth intervals. In order to identify the depths of selected isotherms (e.g. $\left.13^{\circ} \mathrm{C}\right)$, the indices of temperature values within $\pm 0.05^{\circ} \mathrm{C}$ of the desired isotherm (e.g. $13^{\circ} \mathrm{C} \pm 0.05^{\circ} \mathrm{C}$ ) were identified and the corresponding depth and time values were extracted.

Current magnitude and direction. We deployed 3 upward-looking RDI $600 \mathrm{kHz}$ acoustic Doppler current
Table 1. Deployment depths (meters from bottom) of Onset XTI temperature loggers on alongshore thermistor chains at Sites A1, A2/X3, A3 and A4 and on cross-shore thermistor chains at Sites X1, X2, A2/X3 and X4

\begin{tabular}{|lcccccc|}
\hline A1 & A2/X3 & A3 & A4 & X1 & X2 & X4 \\
\hline 20 & 20 & 20 & 20 & 60 & 40 & 4 \\
17 & 14 & 15 & 16.5 & 50 & 30 & 1 \\
9 & 8 & 8 & 14 & 40 & 20 & \\
1 & 1 & 1 & 11.5 & 20 & 1 & \\
& & & 9 & & & \\
& & & 6.5 & & & \\
& & & 1.5 & & & \\
& & & & & & \\
\hline
\end{tabular}

profilers (ADCPs) at Alongshore Sites A1, A2, and A3 in $\sim 20 \mathrm{~m}$ of water. The ADCPs were bolted via PVC frames to pipes jetted into the sandy seafloor, which made the ADCPs extremely stable. Measurements of current magnitude and direction along with acoustic backscatter intensity were made at $1 \mathrm{~m}$ intervals from $3 \mathrm{~m}$ above the bottom to within $1 \mathrm{~m}$ of the surface. The ADCPs averaged 40 pings $10 \mathrm{~min}^{-1}(0.00167 \mathrm{~Hz})$ providing observations of currents and backscatter at 16 elevations above the bottom. Time series of ADCP data were pre-processed by removing all data when the beam correlation dropped below $80 \%$. One upwardfacing Nortek $1000 \mathrm{kHz}$ ADCP was also deployed in $\sim 20 \mathrm{~m}$ of water at Alongshore Site A4.

Wind. Hourly wind speed and direction were obtained from the National Data Buoy Center's Monterey Buoy \#46042 located roughly 27 nautical miles offshore (Fig. 1).

Calculation of variance-conserving power spectra. The variance-conserving power spectra were determined in 2 steps. The first step applies an infinite impulse response (IIR), discrete, fast Fourier transform, set-order, digital filter. The second step utilizes an ensemble- and band-averaging power autospectrum that applies a Hanning window with $50 \%$ overlap and a linear detrend to replace the truncated degrees of freedom and thus increase the reliability of the results.

\section{RESULTS}

This paper focuses on measurements from an $11 \mathrm{~d}$ period from midnight on 17 August to midnight on 28 August (Fig. 3). This time frame was chosen because of the persistent upwelling-favorable winds during that period. Zooplankton in Monterey Bay exhibit nightly diel migrations (Table 2). During the time frame covered by this study, zooplankton were observed to migrate from the benthos or near benthos into the water column in the evening hours. During the evening hours, zooplankton were located throughout 

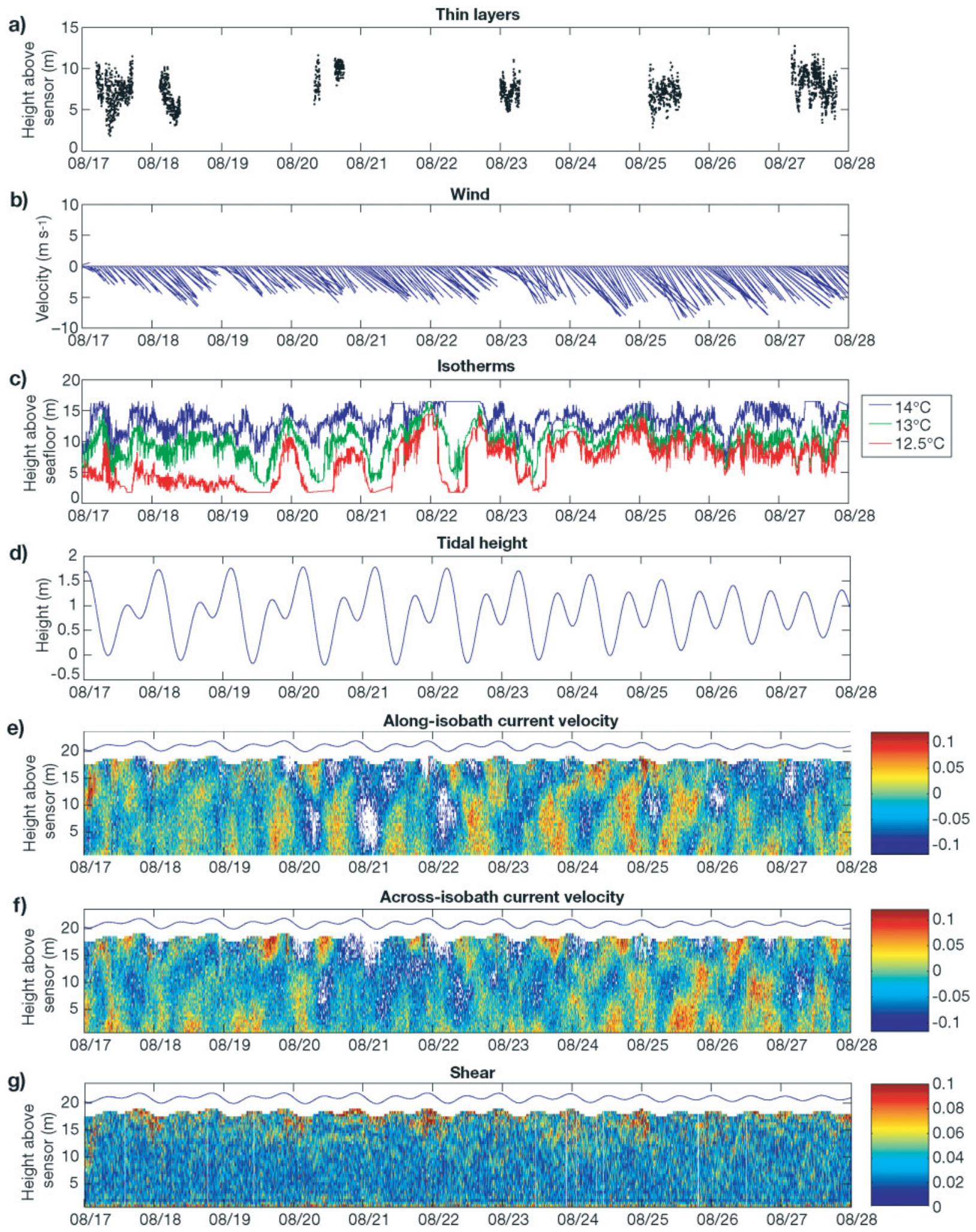

Fig. 3. Time series of data from midnight on 17 August to midnight on 28 August 2002: (a) thin zooplankton layer depth (m); (b) hourly wind speed $\left(\mathrm{m} \mathrm{s}^{-1}\right)$ and direction from NDBC Monterey Buoy \#46042 (north is positive, south negative); (c) isotherms $\left(12.5,13,14^{\circ} \mathrm{C}\right) ;(\mathrm{d})$ hourly tidal height $(\mathrm{m})$ at MBARI tide gauge at Moss Landing harbor; (e) along-isobath (NW[+] to SE[-]) current velocity $\left(\mathrm{m} \mathrm{s}^{-1}\right)$ measured at Site A2/X3; (f) across-isobath (NE[+] to SW[-]]) current velocity (m s$\left.{ }^{-1}\right)$ measured at Site $\mathrm{A} 2 / \mathrm{X} 3 ;(\mathrm{g})$ shear $\left(\mathrm{s}^{-1}\right)$ calculated after Itsweire et al. (1989). Dates are mo/d 
Table 2. Nightly diel migration of zooplankton from benthos or near benthos into water column, showing start and end times of diel migration

\begin{tabular}{|lcccc|}
\hline $\begin{array}{l}\text { Date } \\
\text { (Aug }\end{array}$ & \multicolumn{2}{c}{ Time of } & migration & end of \\
$2002)$ & start & civil twilight & $\begin{array}{c}\text { Time (next day) of } \\
\text { migration } \\
\text { end }\end{array}$ & $\begin{array}{c}\text { beginning of } \\
\text { civil twilight }\end{array}$ \\
\hline 17 & $20: 30$ & $20: 25$ & $04: 30$ & $06: 00$ \\
18 & $22: 00$ & $20: 23$ & $03: 00$ & $06: 01$ \\
19 & $21: 00$ & $20: 22$ & $04: 00$ & $06: 02$ \\
20 & $21: 00$ & $20: 20$ & $03: 00$ & $06: 03$ \\
21 & $21: 00$ & $20: 19$ & $03: 00$ & $06: 04$ \\
22 & $21: 00$ & $20: 18$ & $03: 00$ & $06: 05$ \\
23 & $21: 30$ & $20: 16$ & $03: 00$ & $06: 05$ \\
24 & $22: 30$ & $20: 15$ & $03: 00$ & $06: 06$ \\
25 & $22: 30$ & $20: 13$ & $02: 00$ & $06: 07$ \\
26 & $20: 00$ & $20: 12$ & $04: 00$ & $06: 08$ \\
27 & $20: 30$ & $20: 10$ & $02: 00$ & $06: 09$ \\
\hline
\end{tabular}

the water column, and no thin layers were observed to form during this time. The average time of the start of this migration was $21: 15 \mathrm{~h}$, roughly $45 \mathrm{~min}$ after the end of civil twilight. The average time of the end of this migration was 03:15 h, roughly $1 \mathrm{~h} 45 \mathrm{~min}$ before the start of civil twilight (U.S. Naval Observatory http:// aa.usno.navy.mil/data/docs/RS_OneDay.html).

We observed 7 thin zooplankton layers between 17 and 28 August (Fig. 3a). Thin zooplankton layers persisted throughout daylight hours, but dissipated during evening hours and reformed during daylight hours in phase with the nightly diel migration. These layers ranged in vertical thickness from $\sim 30 \mathrm{~cm}$ to $4 \mathrm{~m}$, with an overall average thickness of $1.01 \mathrm{~m}$ (Table 3 ), and persisted for time frames of $1 \mathrm{~h} 45 \mathrm{~min}$ to $15 \mathrm{~h} 30 \mathrm{~min}$, with an average time of 8 h 12 min (Table 3, Fig. 3a). Throughout this study, all zooplankton layers were located mid-water column, between 5 and $10 \mathrm{~m}$ above the bottom, in a $22 \mathrm{~m}$ water column.

During this study period, winds were upwellingfavorable ( 304 to $325^{\circ}$ from the NW) ranging from 4.93 to $7.93 \mathrm{~m} \mathrm{~s}^{-1}$, with an average wind velocity of $6.45 \mathrm{~m}$ $\mathrm{s}^{-1}$ (Table 3, Fig. 3b). Tides over this period progressed from a spring tide with a maximum tidal range of $1.9 \mathrm{~m}$ on 20 August, to a neap tide with a minimal tidal range of $0.9 \mathrm{~m}$ on the evening of 26 August (Fig. 3d).

Buoyancy frequency $\left(N^{2}\right)$, shear, and Richardson number (Ri) were calculated from physical measurements made at the approximate depth interval of each thin layer, for the entire duration of the layer. These variables were also calculated for regions above and below each thin zooplankton layer. The 'above' region constitutes physical data starting $1 \mathrm{~m}$ above the thin layer and extending to the surface, and the 'below' region physical data starting $1 \mathrm{~m}$ below the thin layer and extending to the bottom. Buoyancy frequency, shear, and Richardson number were calculated from both the 'above' and 'below' regions for the entire duration of the layer.

Thin zooplankton layers were located in regions with buoyancy frequencies averaging $\left.0.00041(\mathrm{rad} \mathrm{s})^{-1}\right)^{2}$ (Table 3). The average buoyancy frequency above and below the thin layer was 0.00023 and $0.00034\left(\mathrm{rad} \mathrm{s}^{-1}\right)^{2}$, respectively. While all buoyancy frequencies calculated over the $11 \mathrm{~d}$ period were low, the highest relative buoyancy frequencies were found in conjunction with thin zooplankton layers. Thin zooplankton layers occurred in regions with moderate shear $(0.025$ to $0.05 \mathrm{~s}^{-1}$ ). The average shear where layers were located was $0.03830 \mathrm{~s}^{-1}$ (Table 3), while the average shear above and below the layer was 0.03198 and $0.04629 \mathrm{~s}^{-1}$, respectively. Layers were only found in regions where the Richardson number was $>0.25$ (Table 3 ). In general, when the Richardson number is $<0.25$ the water column is unstable (Mann \& Lazier 1996), and will not support thin layers (Dekshenieks et al. 2001).

\section{Organisms in the layers}

Our original objective for the deployment of the TAPS at multiple coastal ocean sites around the con-

Table 3. Layer statistics showing minimum, maximum and average layer thickness (or vertical extent), and wind velocity (veloc.) and direction (dir.) averaged over entire duration of relevant layer. Buoyancy frequency $\left(N^{2}\right)$, shear, and Richardson number (Ri) were calculated from physical measurements made at approximate depth interval of each thin layer and averaged over entire duration of layer. Maximum vertical displacement (Max. v. displ.) represents maximum vertical excursion of layer at any one time

\begin{tabular}{|c|c|c|c|c|c|c|c|c|c|c|c|}
\hline $\begin{array}{l}\text { Layer } \\
\text { no. }\end{array}$ & $\begin{array}{c}\text { Date } \\
\text { (Aug 2002) }\end{array}$ & $\begin{array}{r}\mathrm{T} \\
\min .\end{array}$ & $\begin{array}{l}\text { ckness } \\
\text { max. }\end{array}$ & $\begin{array}{l}\text { m) } \\
\text { avg. }\end{array}$ & $\begin{array}{c}\text { Duration } \\
\text { (h/min) }\end{array}$ & $\operatorname{dir} .\left(^{\circ}\right)$ & $\begin{array}{l}\text { Wind } \\
\text { veloc. }\left(\mathrm{m} \mathrm{s}^{-1}\right)\end{array}$ & $\begin{array}{c}N^{2} \\
\left.(\operatorname{rad~s})^{-1}\right)^{2}\end{array}$ & $\begin{array}{l}\text { Shear } \\
\left(\mathrm{s}^{-1}\right)\end{array}$ & $\mathrm{Ri}$ & $\begin{array}{l}\text { Max. v. } \\
\text { displ. (m) }\end{array}$ \\
\hline 1 & 17 & 0.5 & 4.0 & 1.0 & $12 / 30$ & 314 & 6.17 & 0.00039 & 0.0373 & 1.22 & 8 \\
\hline 2 & 18 & 1.0 & 3.9 & 1.5 & $7 / 00$ & 313 & 4.93 & 0.00053 & 0.0491 & 1.68 & 6 \\
\hline 3 & 20 & 0.8 & 2.0 & 1.0 & $1 / 45$ & 319 & 5.15 & 0.00031 & 0.0317 & 0.30 & 5 \\
\hline 4 & 20 & $<0.3$ & 1.0 & 0.5 & $3 / 10$ & 304 & 7.93 & 0.00022 & 0.0290 & 0.46 & 4 \\
\hline 5 & 23 & $<0.3$ & 1.5 & 0.8 & $6 / 45$ & 325 & 6.53 & 0.00056 & 0.0491 & 19.10 & 4 \\
\hline 6 & 25 & 0.8 & 3.6 & 1.3 & $10 / 45$ & 322 & 7.67 & 0.00050 & 0.0361 & 1.41 & 5 \\
\hline 7 & 27 & $<0.3$ & 2.5 & 1.0 & $15 / 30$ & 311 & 6.83 & 0.00035 & 0.0358 & 1.35 & 6 \\
\hline
\end{tabular}


tinental US was simply to detect the presence or absence of thin high-frequency acoustical scattering layers, and to obtain an indication of their frequency of occurrence at each site we monitored. Our project comprised assessing a number of different candidate coastal locations, environments and seasons for a detailed process study on thin layers that took place in 2005. As a consequence of our original objective, we collected only limited numbers of conventional net samples (e.g. oblique tows) at a few of the coastal sites. These net samples were only intended to collect organisms that were present in large numbers and were representative of the most abundant species and organism shapes in the small zooplankton community. From the shape of the highly abundant organisms at a site, one can attempt to apportion acoustical estimates of biomass between different shape classes (e.g. spherical copepods versus elongate mysids/euphausids). None of the net samples were intended to be quantitative. Although a companion conventional sampling program would have been useful, it was beyond the scope and objective of our project. However, we can use the measurements of acoustical volume scattering strengths to make estimates of the abundances, sizes and shapes of the organisms that were present in and around the thin layers.

Based on visual observations of the zooplankters collected in net samples, we chose 2 scattering models for an inverse calculation to apportion biomass between 2 common shapes for small zooplankton (spherical versus elongate), size spectra being determined for each. The first model, the truncated fluid sphere model, describes scattering due to small crustaceans (e.g. copepods) (Costello et al. 1989). The second model uses the Distorted Wave Born Approximation (DWBA) elongate model method to estimate volume scattering spectra for elongate shaped organisms such as mysids or euphausiids. The inverse code optimally and simultaneously apportions the energy in the acoustic volume scattering strength spectra for each selected time and depth interval into sizes supplied by the user for each of these shapes (Holliday 1977, Holliday et al. 2003).

An inverse calculation was performed for each time-depth sample within range of the boxed region in Fig. 4a. The calculation revealed that the layer was not comprised of scatterers best modeled with a fluid
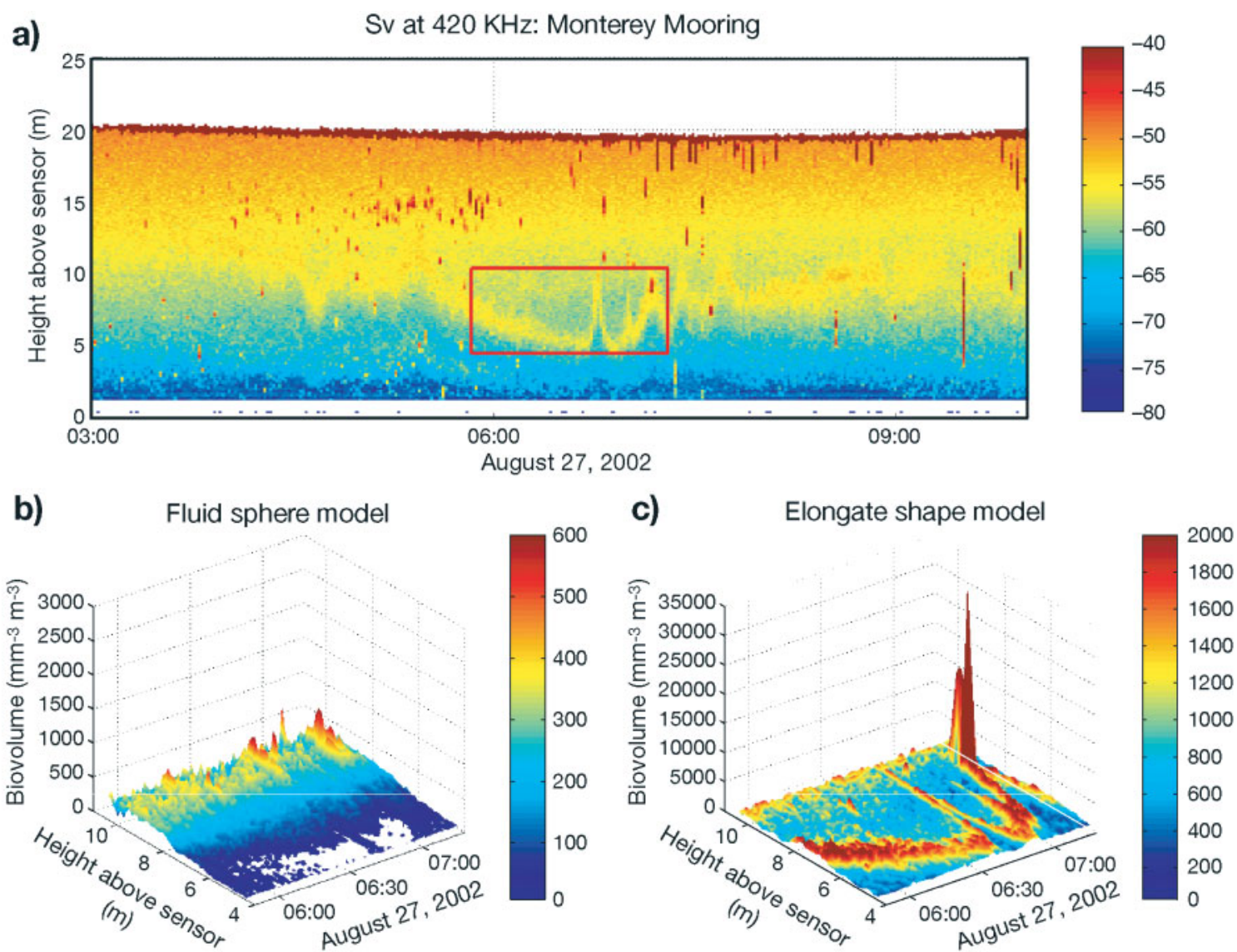

Fig. 4. (a) Time series of acoustic scattering from the TAPS at $420 \mathrm{kHz}$. Elongate and fluid sphere models were run in the red box region; (b, c) results from the (b) fluid sphere model and (c) elongate model showing biovolume versus height above sensor and time (h:min). Note different $z$-axis values 
sphere approach, such as copepods, but by elongate organisms with shapes similar to that of marine crustaceans such as mysids or euphausiids (Fig. 4b,c). Curiously, the small copepod-shaped organisms were not in the layer but were distributed in a secondary structure 1 to $5 \mathrm{~m}$ above the layer at significantly reduced biovolumes. Biovolume is analogous to a net-sampled displacement volume and is a common measure derived from acoustical methods that can be related to biomass.

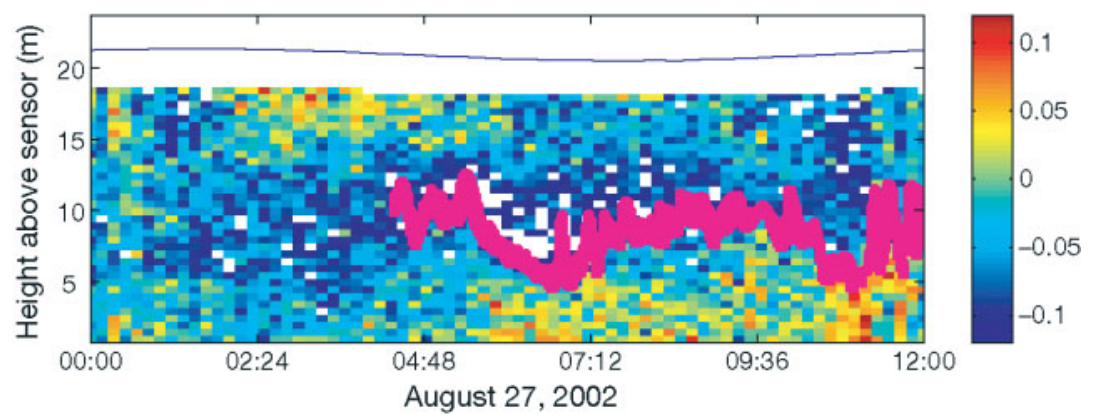

Fig. 5. Across-isobath current velocity $\left(\mathrm{m} \mathrm{s}^{-1}\right): 12 \mathrm{~h}$ time series overlaid with location and thickness of thin zooplankton layer (pink). Abscissas show time of day (h:min). Currents moving toward shore are negative $(-)$; those moving away from shore are positive (+)

\section{Thin zooplankton layers and current structure}

The predominant direction of flow at Sites A1, A2, A3 and A4 was along-isobath; this agrees with previous work by Storlazzi et al. (2003). Current velocities in the along-isobath (NW [+] to SE [-]) direction ranged from +20 to $-20 \mathrm{~cm} \mathrm{~s}^{-1}$, while current velocities in the across-isobath (NE [+] to SW [-]) direction ranged from +12 to $-12 \mathrm{~cm} \mathrm{~s}^{-1}$ (Fig. 3e,f). The average shear at all sites (calculated after Itsweire et al. 1989) was $0.03 \mathrm{~s}^{-1}$, with highest shear values exceeding $0.08 \mathrm{~s}^{-1}$ in the top $4 \mathrm{~m}$ of the water column (Fig. 3g).

Thin zooplankton layers were located either within the 'layer of no motion', between 2 oppositely moving bodies of water, or in regions with low current velocities $\left(<6 \mathrm{~cm} \mathrm{~s}^{-1}\right)$. A $6 \mathrm{~h}$ time series of cross-shore current velocity $\left(\mathrm{m} \mathrm{s}^{-1}\right)$ overlaid with the location of a thin zooplankton layer is shown in Fig. 5, which shows a typical relationship between current structure and thin zooplankton layer position in the water column. Similar distributions were observed during a simultaneous TAPS/ADCP deployment in the Santa Barbara Channel during the summer of 2003 (D. V. Holliday \& C. F. Greenlaw unpubl. data). In Monterey Bay, the water column was stratified during the neap tide, and at this time thin layers were closely associated with the layer of no motion, positioned between winddriven surface flows and tidally-influenced bottom flows. During the spring tide, thin layers were also found in regions with low current velocities $1<6 \mathrm{~cm}$ $\mathrm{s}^{-1}$ ). At all times during the study period, thin layers were located mid-water column, in regions where shear was moderate (0.025 to $\left.0.05 \mathrm{~s}^{-1}\right)$.

\section{Model results}

A model was developed to calculate the distance a particle would be transported if it were located above, within or below the thin zooplankton layer. Current magnitude and direction were derived from an upward-looking $600 \mathrm{kHz}$ ADCP. Thin layer depth was determined from the TAPS data. We ran 3 simulations using data from 27 August 2002 between 06:00 and 12:00 h. In the first simulation, a particle was released within the layer and required to remain at the same depth of the layer for the duration of the simulation. The model was run for $6 \mathrm{~h}$, using 10 min time steps. At the end of the simulation, the particle was advected $292 \mathrm{~m}$ to the $\mathrm{E}$. In the second simulation, a particle was released $4 \mathrm{~m}$ above the layer and required to maintain its position $4 \mathrm{~m}$ above the fluctuating layer for the duration of the $6 \mathrm{~h}$ simulation. Again, the model was run for $6 \mathrm{~h}$ using $10 \mathrm{~min}$ time steps. At the end of the simulation, the particle was advected $2707 \mathrm{~m}$ to the $\mathrm{NE}$ is an onshore direction. In the final simulation, a particle was released $4 \mathrm{~m}$ below the thin layer and required to maintain its position $4 \mathrm{~m}$ below the fluctuating layer for the duration of the simulation. After a simulation time of $6 \mathrm{~h}$, the particle was advected $1170 \mathrm{~m}$ to the SE. Thus, organisms in the water column above the thin layer were advected 9 times farther than organisms within the thin layer, while organisms in the water column below the thin layer were advected $\sim 4$ times farther than organisms within the thin layer (Table 4). While these simulation results may be intuitive, they reinforce the idea that organisms in thin layer structures may decrease their transport distances by associating themselves with regions of reduced current flow.

Table 4. Particle transport distances calculated with particletracking model for 27 August 2002, between 06:00 and 12:00 h

\begin{tabular}{|lcc|}
\hline Particle release & $\begin{array}{c}\text { Transport } \\
\text { distance }(\mathrm{m})\end{array}$ & $\begin{array}{c}\text { Transport } \\
\text { direction }\end{array}$ \\
\hline Above layer $(+4 \mathrm{~m})$ & 2707 & $\mathrm{NE}$ \\
Within layer & 292 & $\mathrm{E}$ \\
Below layer $(-4 \mathrm{~m})$ & 1170 & $\mathrm{SE}$ \\
\hline
\end{tabular}




\section{Thin zooplankton layers and internal waves}

High-frequency internal waves were prevalent in the temperature data at all thermistor sites during much of the study period. Previous observations have shown that the most energetic internal waves and solitons on continental shelves are associated with internal tides and bores generated near the shelf break (Holloway 1987, Ostrovsky \& Stepanyants 1989), and have also shown that as semi-diurnal internal tides propagate into shallower water, they become increasingly nonlinear and superimposed with higher-frequency nonlinear internal waves. Petruncio et al. (1998) reviewed some aspects of internal tide propagation, generation and behavior in Monterey Bay. They identified the degeneration of a semi-diurnal internal tide as a likely source of high-frequency internal waves.

The direction of reflection of internal waves incident upon a sloping shelf is determined by the relation

$$
\begin{aligned}
& \omega^{2}>f^{2}+N^{2} \alpha^{2} \\
& N^{2}=-\frac{g}{\rho_{0}} \frac{\mathrm{d} \sigma}{\mathrm{d} z}
\end{aligned}
$$

where $\omega$ is the wave angular frequency, $f$ is the Coriolis parameter, $\alpha$ is the bottom slope, $N$ is the buoyancy frequency, $g$ is the acceleration of gravity, $\rho_{0}$ is a reference density, and $\sigma$ is the background potential density. If the above condition for $\omega$ is met, internal waves propagating onshore will reflect shoreward off the bottom and continue into shallower water (Munk 1981). If the above condition is not met, shorewardmoving waves will be reflected back to the deep sea when they encounter the bottom. Given the stratification and bottom slope $(\alpha \sim 0.01)$ observed during the study, the above reflection condition was only narrowly satisfied for the $\mathrm{M}_{2}$ internal tide, indicating that some seaward reflection may have occurred. However, the condition was easily satisfied for high-frequency waves, suggesting any shoreward-propagating waves in this frequency band continued shoreward. These shoreward-propagating internal waves (presumably generated at the shelf break) should be steered by the bathymetry until they become perpendicular to the shoreline, similar to the refraction of surface gravity waves (Pringle \& Brink 1999). In addition, Pringle \& Brink (1999) showed how bottom friction causes depthaveraged (and depth-integrated) wave energy to decrease, ultimately to zero, for a wave propagating onshore.

The partitioning of wave energy into kinetic and potential forms is given by the equation

$$
\frac{K E}{P E}=\frac{\omega^{2}+f^{2}}{\omega^{2}-f^{2}}
$$

where $K E$ is the average kinetic energy per unit volume per wavelength, and $P E$ is the average potential energy per unit volume per wavelength. This equation is appropriate for waves of relatively large horizontal scale (Gill 1982, Chapter 8) similar to those observed in this study. This ratio ranges from $\sim 2$ for the $\mathrm{M}_{2}$ internal tide to $\sim 1$ for high-frequency waves. The wave potential energy per unit volume, expressed as a function of frequency, varied substantially within the cross-shore array (Fig. 6a). Wave potential energy was calculated with the expression

$$
P E=\frac{g^{2} \overline{\rho^{2}}}{2 \rho_{0} N^{2}}
$$

where $\rho$ is the perturbation potential density and the superscripted-bar denotes an average over 1 wavelength (Gill 1982, Chapter 8). In the calculation, time average was substituted for the wavelength average. Potential densities were approximated using the equation of state for seawater, an assumed salinity of 33.5, the in situ temperature, and zero pressure. There is minimal freshwater input to Monterey Bay during the summer months, and thus salinity remains relatively constant (Breaker \& Broenkow 1994). With the exception of Site X4, for which a mid-depth sensor was not available, each spectrum stems from temperature observations made near the center of the pycnocline and is representative of the maximum potential energy per unit volume in the water column. Fig. 6a is plotted in variance-preserving form, showing distinct peaks at the diurnal, semi-diurnal, and quarter-diurnal frequencies, as well as a broad peak centered about a period of approximately $20 \mathrm{~min}$.

The high-frequency potential energy per unit volume in the pycnocline is reduced slightly between the 60 and $40 \mathrm{~m}$ isobaths ( $3 \mathrm{~km}$ distance), and reduced by a factor of 2 between the 40 and $20 \mathrm{~m}$ isobaths ( $2 \mathrm{~km}$ distance), apparently due to frictional dissipation as waves propagate onshore. The approximate depth-integrated, highfrequency internal wave energy (not shown) displays an even larger cross-shore decrease. It is reduced by a factor of 5 from the $60 \mathrm{~m}$ site to the $20 \mathrm{~m}$ site. For comparison, Pringle (1999) noted a 4 -fold decrease in depthintegrated high-frequency internal wave power between the 365 and $130 \mathrm{~m}$ isobaths ( $15 \mathrm{~km}$ distance) for the Coastal Ocean Dynamics Experiment (CODE) study, consistent with frictional dissipation of internal waves moving onshore. The tidal-band potential energy per unit volume increases shoreward, but this should not be interpreted as an increase in total tidal energy with decreasing distance from shore. The depth-integrated tidal-band energy (not shown) is approximately constant from site to site, and the increase shown in Fig. 6a can be understood as a concentration of energy per unit volume due to decreasing water depth. Barotropic tides con- 


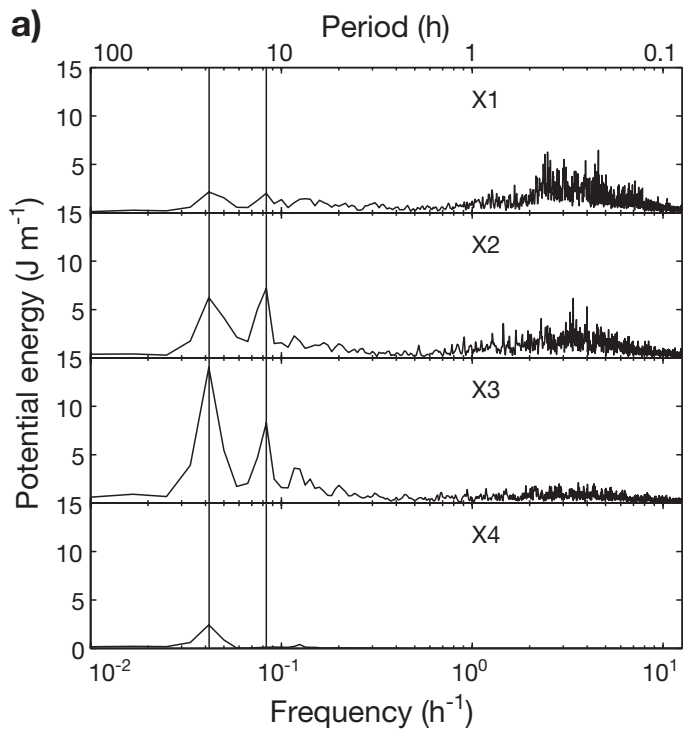

tributed little, if any, to the temperature variance. Assuming a typical barotropic tidal range of $\sim 1 \mathrm{~m}$, the corresponding mid-depth vertical isopycnal displacement would be $\sim 0.5 \mathrm{~m}$ for a formal barotropic mode (Kundu 1990, Chapter 13). Observed displacements inferred from the temperature were much larger, indicating that barotropic tides had negligible direct effects on temperature.

Direct observations of thin zooplankton layers and isotherms (Fig. 6b) show that the depth of the thin zooplankton layer is modulated by the passage of highfrequency internal waves with periods of 18 to $20 \mathrm{~min}$. The smoothed variance-conserving power spectra for the $13^{\circ} \mathrm{C}$ isotherm and the thin layers from Site A4 confirm our direct observations. The dominant frequency in the variance-conserving power spectra for the $13^{\circ} \mathrm{C}$ isotherm is $0.0909 \mathrm{~Hz}$, corresponding to a period of

b) Sv at $420 \mathrm{KHz}$ : Monterey Mooring
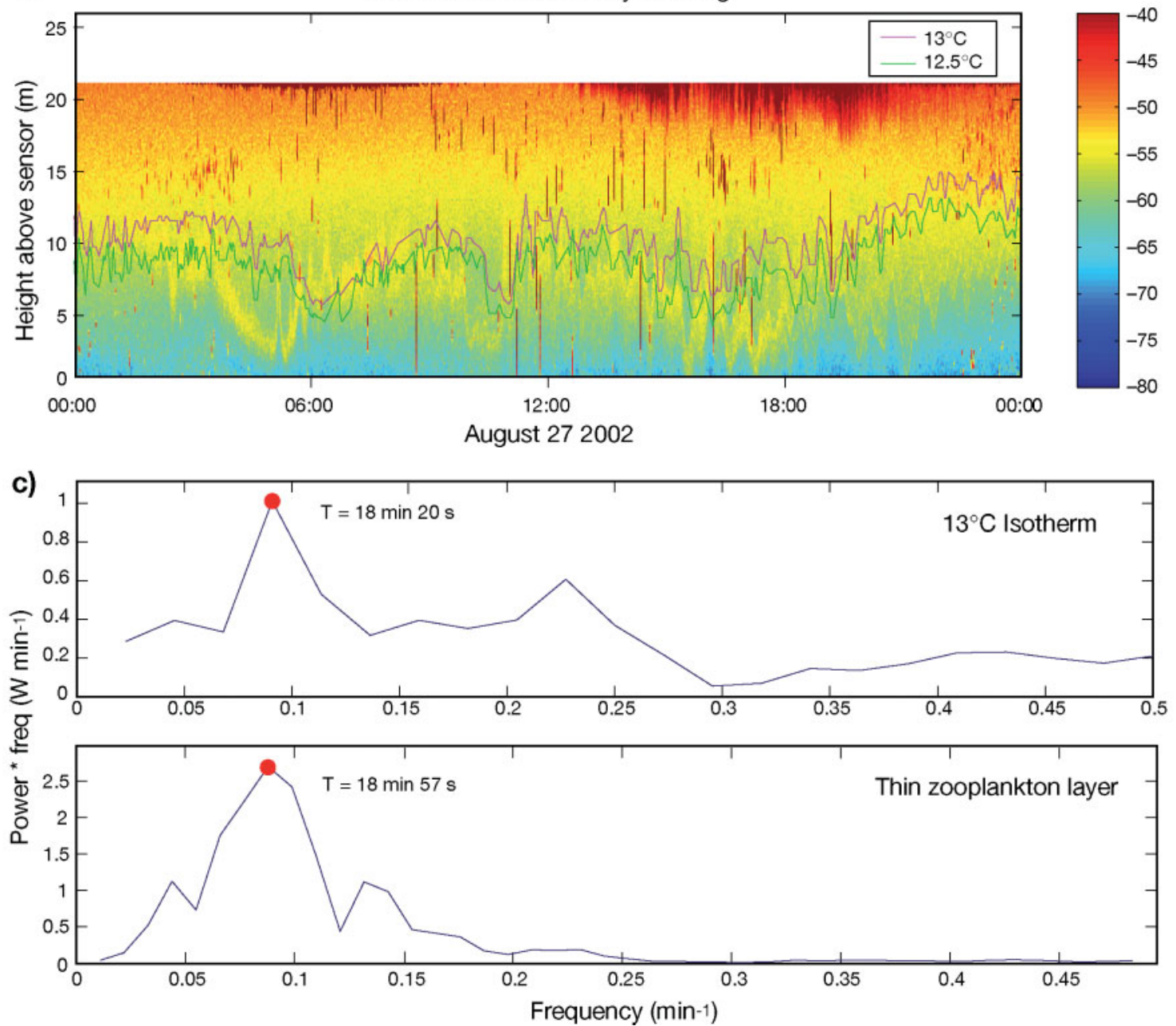

Fig. 6. (a) Potential energy per unit volume in internal waves at 4 sites: X1 (60 m isobath, $20 \mathrm{~m}$ thermistor depth); X2 (40 m isobath, $10 \mathrm{~m}$ thermistor depth); X3 (20 m isobath, $11 \mathrm{~m}$ thermistor depth); X4 (4 m isobath, $1 \mathrm{~m}$ thermistor depth). (b) Time series of acoustic scattering from TAPS at $420 \mathrm{kHz}$ overlaid with $13^{\circ} \mathrm{C}$ isotherm (pink) and $12.5^{\circ} \mathrm{C}$ isotherm (green). (c) Power spectra for $13^{\circ} \mathrm{C}$ isotherm and thin zooplankton layer; dominant period for $13^{\circ} \mathrm{C}$ isotherm is 18 min $20 \mathrm{~s}$, that for the zooplankton layer is $18 \mathrm{~min} 57 \mathrm{~s}$ 
$18 \mathrm{~min} 20 \mathrm{~s}$, while the dominant frequency in the variance conserving power spectra for the thin zooplankton layer is $0.0879 \mathrm{~Hz}$, corresponding to a period of $18 \mathrm{~min} 57 \mathrm{~s}$ (Fig. 6c). Thin zooplankton layers were present across of range of high frequency internal wave displacements, from a minimum displacement of $1.5 \mathrm{~m}$ to a maximum of $8 \mathrm{~m}$. Thus, during this study, internal waves were not a mechanism leading to the dispersion of thin layers. There is, however, a close relationship between internal wave height and the variation in layer thickness over time in that as internal wave height increases, the layer thickness increases.

Plotted in Fig. 7 are internal wave heights and the average vertical thickness of zooplankton layers observed in northern Monterey Bay for the entire study period, 6 August to 9 September 2002. The correlation index $\left(\mathrm{r}^{2}\right)$ for this relationship is 0.394 , thus $\sim 40 \%$ of the variability in average layer thickness can be explained by internal wave height. The calculated $p$-value $(0.0002)$ indicates that this relationship is significant.

\section{Transport of zooplankton by internal waves}

High-frequency, nonlinear internal waves have been proposed as a mechanism for the cross-shore transport of planktonic larvae and post-larval invertebrates in surface waters (Shanks 1983, 1995, Pineda 1999). To arrive at a general estimate of the cross-shore transport associated with internal waves in Monterey Bay, temperature measurements from the thermistor array were analyzed and combined with an analytical model of solitary wave particle transport. While the presence of internal waves was well-defined in thermistor as

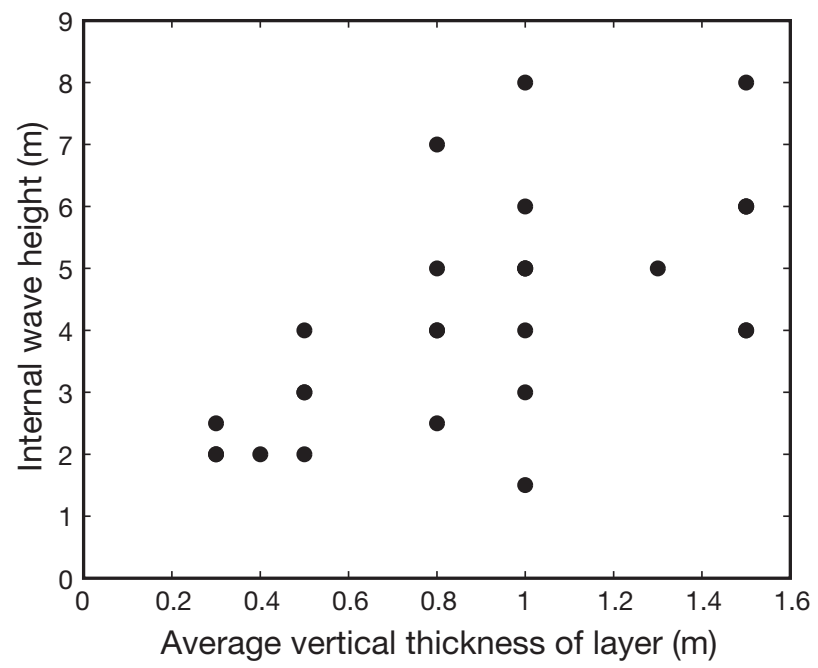

Fig. 7. Internal wave height plotted against average vertical thickness of zooplankton layers observed in northern Monterey Bay over entire study period, 6 August to 9 September 2002 well as TAPS data, internal waves were not wellresolved in ADCP data due to lower sampling rates. Thus, a direct calculation of transport due to internal waves was not possible using ADCP data.

The most well-defined thin layers were isolated for individual analysis of wave parameters. An analytical model, developed by Lamb (1997), was then used to arrive at transport rates and distances. Lamb (1997) presented an expression for the transport experienced by a surface particle advected by a single, nonbreaking, solitary internal wave, whereby the solitary wave is the exact (soliton) solution to the Kortewegde Vries $(\mathrm{KdV})$ equation. Individual wave transport distances were multiplied by the measured dominant wave period to arrive at an approximate transport rate for particles. Realistic high-frequency nonlinear waves on the continental shelf more closely resemble a modified cnoidal wave train than true solitons. However, the use of the soliton solution allows a simple, firstorder estimation of the transport rate, which was our objective. Furthermore, because solitons have no return flow (i.e. no 'backwash') the estimate is likely to be an overestimate and, as such, represents a realistic upper bound of the true transport rate. For a 2-layer fluid, the soliton solution is (after Holloway 1987)

$$
\begin{gathered}
\eta=\eta_{0} \operatorname{sech}^{2}\left(\frac{x-c t}{L}\right) \\
c=c_{0}\left[1+\frac{\eta_{0}}{2}\left(\frac{h_{1}-h_{2}}{h_{1} h_{2}}\right)\right] \\
c_{0}=\left(g \frac{\left(\rho_{2}-\rho_{1}\right)}{\rho_{2}} \frac{h_{1} h_{2}}{h_{1}+h_{2}}\right)^{1 / 2} \\
L^{2}=\frac{4}{3} \frac{h_{1}^{2} h_{2}^{2}}{\left(h_{1}-h_{2}\right) \eta_{0}}
\end{gathered}
$$

where $\eta$ is the deviation of the fluid interface from the unperturbed level, $\eta_{0}$ is the soliton amplitude, $x$ is the horizontal position in the direction of wave propagation, $C$ is the nonlinear wave speed, $c_{0}$ is the linear wave speed, $L$ is the soliton half-width, $g$ is the acceleration of gravity, and $\rho_{i}$ and $h_{i}$ are the layer densities and thicknesses, respectively, for the upper $(i=1)$ and lower $(i=2)$ layers. If $h_{1}<h_{2}$, then $\eta_{0}<0$ and the waves represent a depression of the pycnocline. If $h_{1}>h_{2}$, then $\eta_{0}>0$ and the waves are elevations of the pycnocline. Velocities are oppositely directed between the surface and bottom waters. In this sense, solitary waves are not oscillatory.

Lamb's (1997) expression for the transport distance of a surface particle due to a single soliton can be derived directly from the soliton solution above, and is

$$
\Delta x=2 L\left(\frac{b^{2}}{1-b^{2}}\right)^{1 / 2} \arctan \left[\left(\frac{b^{2}}{1-b^{2}}\right)^{1 / 2}\right]
$$


where $\Delta x$ is the transport distance, and $b^{2}=U_{\max } C^{-1}$. Here $U_{\text {max }}$ is the positive maximum velocity at a fixed depth, such as the surface. A representative $U_{\max }$ for each layer can be found from the equations $u_{1}=c_{0} \eta_{0} h_{1}^{-1}$ and $u_{2}=-c_{0} \eta_{0} h_{2}^{-1}$ (Holloway 1987). The sign of $\Delta x$ in each layer is equal to the sign of $U_{\max }$ in the corresponding layer.

It should be noted that Lamb's (1997) expression is valid only at the surface where there are no depth variations in the horizontal velocity. Many of the tidal velocities observed displayed an approximate Mode 1 structure with oppositely directed fluid in each layer and a near-permanent zero-crossing close to the pycnocline, where thin layers are most frequently observed (Dekshenieks et al. 2001). This tidal structure argues that a Mode 1 structure was present for the high-frequency waves as well. As previously stated, the ADCP at Site A4 could not resolve the high-frequency wave structure due to the relatively low $10 \mathrm{~min}$ sampling rate. In addition, because a mode 1 structure is the simplest available shape for an internal gravity wave (Kundu 1990, Chapter 13), it is the most practical shape to assume. Particles in thin layers near any zero-crossing will have reduced transport rates due to the lack of substantial horizontal velocities. It is also important to remember that the calculated speeds from Lamb's model represent maximums because they are based on the transport associated with a pure solitary wave, which has no return flow.

Surface particle transport distances were estimated over 3 approximate $6 \mathrm{~h}$ periods on 3 separate days with strong internal wave activity, 17, 23, and 25 August. High passed velocities in the array were not wellpolarized in any preferred direction during the study period, making a definition of dominant high-frequency wave propagation difficult. Layer thicknesses, $h_{1}$ and $h_{2}$, were determined from the observed pycnocline. Once layer thickness was defined, layer density was calculated using the equation of state of seawater, a constant salinity of 33.5, and an appropriate weighting of temperature, and zero pressure. Soliton amplitudes were calculated using the standard deviation of the

Table 5. Internal wave transport over three $6 \mathrm{~h}$ periods. $h_{1}$ and $h_{2}$ : layer thicknesses; $\eta_{0}$ : soliton amplitude; $C$ : nonlinear wave speed; $t$ : dominant wave period; $v$ : maximum Lagrangian drift speed; $\Delta x$ : transport distance of particle

\begin{tabular}{|lccccccr|}
\hline $\begin{array}{l}\text { Date } \\
(2002)\end{array}$ & $\begin{array}{c}h_{1} \\
(\mathrm{~m})\end{array}$ & $\begin{array}{c}h_{2} \\
(\mathrm{~m})\end{array}$ & $\begin{array}{c}\eta_{\mathrm{o}} \\
(\mathrm{m})\end{array}$ & $\begin{array}{c}c \\
\left(\mathrm{~cm} \mathrm{~s}^{-1}\right)\end{array}$ & $\begin{array}{c}t \\
(\mathrm{~min})\end{array}$ & $\begin{array}{c}V \\
\left(\mathrm{~cm} \mathrm{~s}^{-1}\right)\end{array}$ & $\begin{array}{r}\Delta x \\
(\mathrm{~m})\end{array}$ \\
\hline Aug 17 & 11.0 & 9.0 & 3.4 & 16.0 & 14.1 & 5.4 & 104 \\
Aug 23 & 8.5 & 11.5 & -3.0 & 14.0 & 12.9 & 4.6 & 90 \\
Aug 25 & 8.5 & 11.5 & -2.6 & 15.0 & 18.6 & 2.8 & 97 \\
\hline
\end{tabular}

interface displacement, as determined from the calculated density of the thermistor nearest the interface and the buoyancy frequency of its neighbors. Dominant wave periods were calculated using the average power-weighted frequency shown by the thermistor closest to the nominal interface depth. Table 5 shows layer thicknesses $\left(h_{1}, h_{2}\right)$, soliton amplitude $\left(\eta_{0}\right)$, nonlinear wave speed $(c)$, dominant wave period $(t)$, maximum Lagrangian drift speed $(v)$ of the 2 layers, and calculated transport distance $(\Delta x)$.

\section{DISCUSSION}

In the past decade, the use of acoustics for the study of zooplankton distribution has seen important advances. These advances stem from the evolution of multifrequency acoustical sensors and from improvements in theories describing scattering from small particles (Holliday et al. 2003). Instruments like the TAPS allow us to resolve zooplankton distributions on vertical spatial scales of $0.125 \mathrm{~m}$ at $1 \mathrm{~min}$ intervals, over periods of months.

In the 1998 Pacific NW study, 3 TAPS were deployed to study zooplankton distribution over a $2 \frac{1}{2}$ mo period. Zooplankton distributions during this study had 2 characteristic features: (1) persistent thin layer structures, and (2) increased numbers of organisms in the water column at night. McManus et al. (2003) suggested a biological mechanism involving foraging behavior that aggregates zooplankton at depths occupied by higher abundances of phytoplankton and microzooplankton to form thin layers. However, there were also times when the zooplankton appeared to avoid thin phytoplankton layers, some of which appeared to contain phytoplankton with toxic attributes, e.g. they contained Pseudo-nitzschia spp. In addition, nightly diel migration of benthopelagic organisms (e.g. mysids) was invoked to explain the increased numbers of organisms throughout the water column each night. Reverse migration from the surface to depth by Pseudocalanus spp. was also a probable factor that modified observed nighttime zooplankton abundances (Kringel et al. 2003, McManus et al. 2003).

While the thin zooplankton layers observed in the Pacific NW study had comparable average thicknesses of $\sim 1 \mathrm{~m}$, they differed in duration from those in the present study (McManus et al. 2003). Thin zooplankton layers in the Pacific NW study persisted on time frames of hours to days, with a maximum duration of $14 \mathrm{~d}$. The difference in the length of time the layers persisted in the present Monterey Bay study and in the Pacific NW study (McManus et al. 2003) was most likely due to differences in species composition of the layers. 


\section{General statistics}

Interesting comparisons can be made between thin phytoplankton layers in the Pacific NW study and thin zooplankton layers in Monterey Bay by examining general characteristics as well as calculations of physical properties made at the exact depth interval of each layer.

Thin phytoplankton layers in the Pacific NW occurred over a broad range of buoyancy frequencies (Dekshenieks et al. 2001). Roughly $40 \%$ of all layers occurred at relatively low buoyancy frequencies of $\left.<0.0005(\mathrm{rad} \mathrm{s})^{-1}\right)^{2}$, while $60 \%$ were in regions with buoyancy frequencies $>0.0005\left(\mathrm{rad} \mathrm{s}^{-1}\right)^{2}$ (Dekshenieks et al. 2001). Thin zooplankton layers in the Monterey Bay study were located in regions of relatively low buoyancy frequencies of $<0.00056\left(\mathrm{rad} \mathrm{s}^{-1}\right)^{2}$, with an average frequency of $\left.0.00041(\mathrm{rad} \mathrm{s})^{-1}\right)^{2}$. While all buoyancy frequencies calculated for the Monterey Bay study were low, the highest relative buoyancy frequencies were found in conjunction with thin layers. This was also observed in the Pacific NW study (Dekshenieks et al. 2001).

Thin phytoplankton layers in the Pacific NW study occurred over a broad range of shear, while thin zooplankton layers in the Monterey Bay study occurred over a narrow range of shear. There were 2 modes in the shear histogram for the Pacific NW study, the first at low shear ( 0 to $0.025 \mathrm{~s}^{-1}$ ) and the second at moderate shear $\left(0.025\right.$ to $\left.0.05 \mathrm{~s}^{-1}\right)$, while $5 \%$ of the layers occurred at a shear $>0.05 \mathrm{~s}^{-1}$ (Dekshenieks et al. 2001). Thin zooplankton layers in the Monterey Bay study occurred only in regions with moderate shear (0.025 to $0.05 \mathrm{~s}^{-1}$ ). The average shear where layers were located was $0.03830 \mathrm{~s}^{-1}$.

While there are subtle differences in the buoyancy frequency and shear values, comparisons of the Richardson number and thin layer location are the same for the 2 coastal areas. In both the Pacific NW and Monterey Bay studies, all layers were located in regions where the Richardson number was $>0.25$. Thus, we would expect thin layers to occur under similar physical conditions in other coastal systems, providing that biological conditions are also favorable.

\section{Organisms in the layers}

Due to the nature and primary objective of our fieldwork in Monterey Bay, we had limited capabilities for direct sampling, especially for large micronekton, whose presence was suggested by the results of the acoustic inverse processing. Thus, we are only able to speculate on which of the organisms that are often present in the area at that time of year were consistent with the results of our acoustical sampling. The results from the inverse scattering models suggest that the organisms in these particular thin layers in Monterey Bay were elongate, and that the acoustical scattering in the layers was dominated by 2 size ranges, 6 to $10 \mathrm{~mm}$ and 15 to $20 \mathrm{~mm}$ in length. In Monterey Bay, the predominant zooplankters in these size classes are juvenile and adult krill, respectively (B. Marinovic pers. comm.). Although many species of krill do not occur in shallow waters, 1 distinct species (Thysanoessa spinifera) is a neritic species, 80 to $90 \%$ of the diet of T. spinifera consists of diatoms, and some dinoflagellates; however, T. spinifera also consume small zooplankton (e.g. copepods) when available. Results from the spherical model show that copepod-sized organisms are located above the thin layer at very low densities. It is possible that the absence of copepodsized organisms in the thin layer is due to grazing pressure by $T$. spinifera.

\section{Thin zooplankton layers and current structure}

In northern Monterey Bay, zooplankton layers were located either within the layer of no motion or in regions with low current velocities $\left(<6 \mathrm{~cm} \mathrm{~s}^{-1}\right)$. This pattern was also observed in the 1996 and 1998 Pacific NW studies (Dekshenieks et al. 2001). In addition, a similar phenomenon has been observed in Santa Barbara (D. V. Holliday \& C. F. Greenlaw unpubl. data). In the Pacific NW study, wind and tidal forcing were the primary influences on circulation patterns in the study area. The surface layer (ranging in depth from 2 to $10 \mathrm{~m}$ ) was forced by the wind, while deeper flows were tidally driven. The majority of thin phytoplankton layers in the fjord were at the density interface between the wind-forced surface layer and the tidally-influenced layer below. Thus, under normal circulation conditions, thin layers were located in regions with relatively low current motion (Dekshenieks et al. 2001).

During the 1996 Pacific NW study, Rines et al. (2002) demonstrated that during normal circulation conditions, populations of the diatom Pseudo-nitzschia spp. persisted and were retained in the upper portion of the fjord. This retention was the result of 2 processes: (1) the Pseudo-nitzschia spp. population was located at the pycnocline, a region of relatively low motion between the wind-forced surface water and tidally dominated subsurface water, and (2) the population was located in a region of the fjord where water recirculates under the predominant wind conditions (McManus et al. 2003).

Similar processes may result in the retention of zooplankton in northern Monterey Bay. As previously mentioned, thin zooplankton layers were located 
either within the layer of no motion or in regions with low current velocities. In addition, during upwellingfavorable winds, a shallow, stratified cyclonic gyre forms in northern Monterey Bay as a dynamic response to upwelling just outside the bay (Graham 1993, Graham \& Largier 1997). This cyclonic gyre has a residence time of 8 to 12 d (Paduan \& Rosenfeld 1996, Graham \& Largier 1997). As in the Pacific NW, the combination of organisms in regions of the water column with low current velocities and a re-circulating gyre will result in the retention of planktonic populations within the system.

\section{Thin zooplankton layers and internal waves}

Our observations show that the vertical depth distribution of thin zooplankton layers is modulated by high-frequency internal waves, with periods of 18 to $20 \mathrm{~min}$. Thin zooplankton layers were present across of range of internal wave heights, from a minimum of $1.5 \mathrm{~m}$ to a maximum of $8 \mathrm{~m}$. Thus, even at the maximum internal wave heights, the thin layers were not dispersed.

Thin zooplankton layers in the 1998 Pacific NW study were dispersed temporarily when current shear and turbulence were enhanced due to the passage of solitons (McManus et al. 2003). These dispersal events were brief and the thin layer rapidly reformed through vertical migration (within a $\sim 1 \mathrm{~h}$ time frame). In the Pacific NW study zooplankton swimming speeds were high enough to overcome the average vertical mixing intensity in the water column. Zooplankton layers were temporarily dispersed only when turbulence levels exceed the speed of vertical migration (McManus et al. 2003).

While we did not observe internal waves dispersing thin zooplankton layers in Monterey Bay, there was a direct relationship between internal wave height and layer thickness over time. As internal wave height increased, layer thickness increased. The passage of the high-amplitude internal waves enhanced current shear and also, most likely, turbulence $(\varepsilon)$. Recent evidence has shown that the water column can be locally turbulent but not support vertical fluxes (Itsweire et al. 1993, Etemad-Shahidi \& Imberger 2001, 2002, Saggio \& Imberger 2001). Thus, it is possible that while heightened turbulence increased layer thickness, the vertical flux was insufficient to completely disperse the layer.

\section{Transport of zooplankton by internal waves}

Internal waves often have a signature at the ocean's surface comprising long bands of foam, or slicks, parallel to the coastline. These bands are often separated by distances of $\sim 100 \mathrm{~m}$, a typical wavelength for highfrequency internal waves (Franks 1997, Storlazzi et al. 2003). Within the bands are surface concentrations of planktonic organisms that can be 6 to 40 times greater than concentrations outside the bands (Shanks 1983). Nonlinear internal waves have been shown to transport planktonic larvae and post-larval invertebrates (Shanks 1983, 1995). Shanks (1983) deployed drogues in long lines perpendicular to visible bands. In 2 of 5 experiments, the drogues were transported 1 to $2 \mathrm{~km}$ shoreward, over time frames of 2 to $3 \mathrm{~h}$. In those experiments where the nonlinear wave transported organisms onshore, the current speed generated by the wave was greater than the rate of advance of the wave (Shanks 1995). Thus, these nonlinear internal waves were capable of some advection (Pineda 1999).

We utilized an analytical model developed by Lamb (1997) to calculate transport distances of surface particles associated with nonlinear internal waves. Using Lamb's model and observational data from 17, 23 and 25 August at Site A4, we found the average shoreward transport distance at the surface was $97 \mathrm{~m}$ over a $6 \mathrm{~h}$ period $\left(\sim 0.45 \mathrm{~cm} \mathrm{~s}^{-1}\right)$. The average rates of transport of surface particles calculated by Lamb's model $(\sim 0.45 \mathrm{~cm}$ $\mathrm{s}^{-1}$ ) are lower than the average rates of transport of surface particles observed by Shanks (1995) ( 13 to $18 \mathrm{~cm}$ $\mathrm{s}^{-1}$ ). Our calculated transport rates are lower because we used an analytical model which accounts only for the transport of particles due to internal wave motion, while Shank's (1995) observations in the coastal ocean accounted for both the transport of particles due to internal wave motion and the simultaneous transport of particles due to surface currents.

While the values given by Lamb's (1997) model are instructive, the majority of thin layers are not located at the surface, but are subsurface at the pycnocline. The transport rates and distances for surface particles will not be the same for that of particles located at the pycnocline. For a mode 1 internal wave in a continuously stratified ocean, the horizontal velocity has a permanent zero-crossing near the pycnocline, where most thin layers are observed. Thus, particle transport rates in thin layers near this zero-crossing will be further reduced compared to those calculated by Lamb's model.

\section{CONCLUSIONS}

It has been demonstrated that thin layers are a recurrent feature in a variety of coastal systems. Thin layers are comprised of phytoplankton, zooplankton and marine snow, as well as marine viruses and bacteria (Donaghay et al. 1992, Johnson et al. 1995, Alldredge et al. 2002, Rines et al. 2002, McManus et al. 2003, 
G. Steward pers. comm.). Prior to this study, the bulk of thin layer research had been done on thin layers of phytoplankton. The purpose of this study was to provide a description of thin zooplankton layers and the concurrent physical conditions under which these layers are observed. We also investigated the role that thin zooplankton layers play in the transport and retention of marine plankton in coastal systems.

During an $11 \mathrm{~d}$ period of persistent upwellingfavorable winds between midnight on 17 August to midnight on 28 August 2002, we observed 7 thin zooplankton layers in Monterey Bay. These zooplankton layers persisted throughout daylight hours, but were observed to dissipate during evening hours and reform again during daylight hours in phase with the nightly diel migration. An analysis of acoustical data revealed that the layers were comprised by elongate organisms with shapes similar to that of marine crustaceans such as mysids or euphausiids. Curiously, small copepodsized organisms were not in the layers, but were distributed in a secondary structure 1 to $5 \mathrm{~m}$ above the layers at significantly reduced biovolumes. It is possible that the absence of small copepod-sized organisms in the thin layer was due to grazing pressure.

Thin zooplankton layers were located in regions with buoyancy frequencies averaging $\left.0.00041(\mathrm{rad} \mathrm{s})^{-1}\right)^{2}$. While all buoyancy frequencies calculated over the $11 \mathrm{~d}$ period were low, the highest relative buoyancy frequencies were found in conjunction with thin zooplankton layers. Thin zooplankton layers occurred in regions with moderate shear $\left(0.025\right.$ to $\left.0.05 \mathrm{~s}^{-1}\right)$. All thin layers were located in regions where the Richardson number was $>0.25$. In general, when the Richardson number is $>0.25$ the water column is stable and capable of supporting thin phytoplankton layer development. These results are in agreement with those of a similar study of physical processes and thin phytoplankton layers from the Pacific NW (Dekshenieks et al. 2001). Thus, we would expect thin layers to occur under similar physical conditions in other coastal systems, providing that biological conditions are also favorable.

Thin zooplankton layers were located either within the 'layer of no motion', between 2 oppositely moving bodies of water, or in regions with low current velocities. Similar patterns have been observed in the Pacific NW (Holliday et al. 2003, McManus et al. 2003) and off the coast of Santa Barbara (D. V. Holliday \& C. F. Greenlaw unpubl. data). We developed a particletracking model to calculate the distance a particle would be transported if it were located above, within or below the thin zooplankton layer. Average transport rates were $12.5,1.35$ and $5.4 \mathrm{~cm} \mathrm{~s}^{-1}$, respectively. Organisms in the water column above the thin layer were advected $\sim 9$ times farther than organisms within the thin layer, while organisms in the water column below the thin layer were advected $\sim 4$ times farther than organisms within the thin layer. While these simulation results may be intuitive, they reinforce the idea that organisms in thin layer structures decrease their transport distances by associating themselves with regions of reduced current flow.

In addition to the relationship between thin layers and current structure, our observations revealed that the vertical depth distribution of thin zooplankton layers was modulated by high-frequency internal waves with periods of 18 to $20 \mathrm{~min}$. While thin zooplankton layers were present across a range of internal wave heights, from a minimum of $1.5 \mathrm{~m}$ to a maximum of $8 \mathrm{~m}$, even at maximum observed internal wave heights, the thin layers were not dispersed by internal wave activity. We utilized an analytical model, developed by Lamb (1997), to calculate surface particle transport rates caused by internal waves in the system. Lamb's model determined the average transport rate of a surface particle due to internal wave motion in Monterey Bay to be $0.45 \mathrm{~cm} \mathrm{~s}^{-1}$. As expected, the transport rates due to internal wave motion alone are lower than the transport rates due to current motion. While the values given by Lamb's model were instructive, the majority of thin layers are not located at the surface, but below the surface at the pycnocline. The transport rates for surface particles will not be the same for particles located at the pycnocline. For a Mode 1 internal wave in a continuously stratified ocean, the horizontal velocity has a permanent zero-crossing near the pycnocline, where most thin layers are observed. For particles in thin layers near this zero-crossing, this would result in further reduced transport rates compared to those calculated by Lamb's model.

Results from this study clearly show an association between physical structure, physical processes and the presence of thin zooplankton layers in Monterey Bay. They are comparable to results from the Pacific NW study (Dekshenieks et al. 2001), which clearly showed an association between physical structure, physical processes and the presence of thin phytoplankton layers. It is important to keep in mind that while thin zooplankton layers are associated with coastal circulation patterns, multiple mechanisms (including behavior) contribute to the formation, depth distribution and dissipation of thin layers of zooplankton. With this new understanding we may identify other coastal regions with a high probability of supporting thin layer development, and begin to understand the ecological significance of these structures in the coastal ocean.

Acknowledgements. We thank M. Carr, J. Eckman, J. Figurski, J. Freiwald, J. Grover, T. Kleinwaks, D. McCormack, P. McEnaney, B. Marinovic, J. Miksis, P. Raimondi, G. Stew- 
ard, J. Sullivan, A. VanderWoude and the Santa Cruz Harbormaster for their participation and support in the field study and helpful discussions. Special thanks to J. Lacy and 2 anonymous reviewers for their constructive and helpful comments. This research was supported by the Office of Naval Research Physical Oceanography Program, award \# N00014-01-1-0206 (MAM), the Partnership for Interdisciplinary Studies of Coastal Oceans, a long-term ecological consortium funded by the David and Lucile Packard Foundation (MAM), and the Office of Naval Research Biological/Chemical Oceanography Program, award \# N00014-00-D-0122 (DVH). C. Storlazzi contributed as part of the US Geological Survey's Central California Regional Synthesis Project. This activity was conducted under National Marine Sanctuary Permit MBNMS-2002-016.

\section{LITERATURE CITED}

Alldredge AL, Cowles TJ, MacIntyre S, Rines JEB and 6 others (2002) Occurrence and mechanism of formation of a dramatic thin layer of marine snow in a shallow Pacific fjord. Mar Ecol Prog Ser 233:1-12

Breaker LC, Broenkow WW (1994) The circulation of Monterey Bay and related processes. Oceanogr Mar Biol Annu Rev 32:1-64

Cassie RM (1963) Multivariate analysis in the interpretation of numerical plankton data. NZ J Sci 6:36-59

Costello JH, Pieper RE, Holliday DV (1989) Comparison of acoustic and pump sampling techniques for the analysis of zooplankton distributions. J Plankton Res 11:703-709

Cowles TJ, Desiderio RA (1993) Resolution of biological microstructure through in situ fluorescence emission spectra:an oceanographic application using optical fibers. Oceanography 6:105-111

Dekshenieks MM, Donaghay PL, Sullivan JM, Rines JEB, Osborn TR, Twardowski MS (2001) Temporal and spatial occurrence of thin phytoplankton layers in relation to physical processes. Mar Ecol Prog Ser 223:61-71

Donaghay PL, Osborn TR (1997). Toward a theory of biological-physical control of harmful algal bloom dynamics and impacts. Limnol Oceanogr 42:1283-1296

Donaghay PL, Rines HM, Seiburth J McN (1992) Simultaneous sampling of fine scale biological, chemical and physical structure in stratified waters. Ergeb Limnol 36:97-108

Drake PJ, McManus MA, Storlazzi C (2005) Local wind forcing of the Monterey Bay area inner shelf. Contin Shelf Res 25:397-417

Etemad-Shahidi A, Imberger J (2001) Anatomy of turbulence in thermally stratified lakes. Limnol Oceanogr 46: $1158-1170$

Etemad-Shahidi A, Imberger J (2002) Anatomy of turbulence in a narrow and strongly stratified estuary. J Geophys Res C Oceans 107:10.1029/2001JC000977

Franks PJS (1997) Spatial patterns in dense algal blooms. Limnol Oceanogr 42:1297-1305

Gill AE (1982) Atmosphere-ocean dynamics, Academic Press, New York

Graham WM (1993) Spatio-temporal scale assessment of an 'upwelling shadow' in northern Monterey Bay, California. Estuaries 16:83-91

Graham WM, Largier JL (1997) Upwelling shadows as nearshore retention sites: the example of northern Monterey Bay. Contin Shelf Res 17:509-532

Hanson AK Jr, Donaghay PL (1998) Micro- to fine-scale chemical gradients and layers in stratified coastal waters. Oceanography 11:10-17
Haury LR, McGowan JA, Wiebe PH (1978) Patterns and processes in the time-space scales of plankton distributions. In: Steele JH (ed) Spatial patterns in plankton communities. Plenum Press, New York, p 277-327

Holliday DV (1977) Extracting bio-physical information for the acoustic signatures of marine organisms. In: Anderson NR, Zahuranec BJ (eds) Ocean sound scattering prediction. Plenum Press, New York, p 619-624

Holliday DV, Pieper RE (1980) Volume scattering strengths and zooplankton distributions at acoustic frequencies between 0.5 and $3 \mathrm{MHz}$. J Acoust Soc Am 67:135-145

Holliday DV, Pieper RE, Greenlaw CF, Dawson JK (1998) Acoustical sensing of small scale vertical structures in zooplankton assemblages. Oceanography 11:18-23

Holliday DV, Donaghay PL, Greenlaw CF, McGehee DE, McManus MA, Sullivan JM, Miksis JL (2003) Advances in defining fine- and micro-scale pattern in marine plankton. Aquat Living Resour 16:131-136

Holloway PE (1987) Internal hydraulic jumps and solitons at a shelf break region on the Australian North West Shelf. J Geophys Res C 92:5405-5416

Itsweire EC, Osborn TR, Stanton TP (1989) Horizontal distribution and characteristics of shear layers in the seasonal thermocline. J Phys Oceanogr 19:301-320

Itsweire EC, Koseff JR, Briggs DA, Ferziger JH (1993) Turbulence in stratified-shear flows: implications for interpreting shear-induced mixing in the ocean. J Phys Oceanogr 23:1508-1522

Johnson PW, Donaghay PL, Small EB, Sieburth JM (1995) Ultrastructure and ecology of Perispira ovum (Ciliophora: litostomota): an aerobic, planktonic ciliate that sequesters the chloroplasts, mitochondria and paramylon of Euglena proxima in a micro-oxic habitat. J Eukaryot Microbiol 42: 323-335

Kringel K, Jumars PA, Holliday DV (2003) A shallow scattering layer: high-resolution acoustic analysis of nocturnal vertical migration from the seabed. Limnol Oceanogr 48: 1223-1234

Kudela RM, Chavez FP (2000) Modeling the impact of the 1992 El Niño on new production in Monterey Bay, California. Deep-Sea Res II 47:1055-1076

Kundu PK (1990) Fluid mechanics. Academic Press, San Diego

Lamb KG (1997) Particle transport by non-breaking, solitary internal waves. J Geophys Res C 102:18641-18660

Mann KH, Lazier JRN (1996) Dynamics of marine ecosystems: biological-physical interactions in the oceans, 2nd edn. Blackwell Scientific Publications, Boston

Marine Zooplankton Colloquium 2 (2001) Future of marine zooplankton research-a perspective. Mar Ecol Prog Ser 222:297-308

McManus MA, Alldredge AL, Barnard A, Boss E and 21 others (2003) Characteristics, distribution and persistence of thin layers over a 48 hour period. Mar Ecol Prog Ser 261: $1-19$

Munk M (1981) Internal waves and small-scale processes. In: Warren B, Wunsch C (eds) Evolution of physical oceanography. MIT Press, Boston

Ostrovsky LA, Stepanyants YA (1989) Do internal solitons exist in the ocean? Rev Geophys 27:293-310

Paduan JD, Rosenfeld LK (1996) Remotely sensed surface currents in Monterey Bay from shore-based HF radar (coastal ocean dynamics application radar). J Geophys Res 101: 20669-20686

Paffenhöfer GA, Sherman BK, Lee TN (1987) Abundance, distribution and patch formation of zooplankton. Progr Oceanogr 19:403-436

Petruncio ET, Rosenfeld LK, Paduan JD (1998) Observation 
of the internal tide in Monterey Canyon. J Oceanogr 28: $1873-1903$

Pineda J (1999) Circulation and larval distribution in internal tidal bore warm fronts. Limnol Oceanogr 44:1400-1414

Pringle JM (1999) Observations of high-frequency internal waves in the Coastal Ocean Dynamics Region. J Geophys Res C 104:5263-5281

Pringle JM, Brink KH (1999) High frequency internal waves on a sloping shelf. J Geophys Res C 104:5283-5299

Rines JEB, Donaghay PL, Dekshenieks MM, Sullivan JM, Twardowski MS (2002) Thin layers and camouflage: hidden Pseudo-nitzschia spp. (Bacillariophyceae) populations in a fjord in the San Juan Islands, Washington, USA. Mar Ecol Prog Ser 225:123-137

Saggio A, Imberger J (2001) Mixing in turbulent fluxes in the metalimnion of a stratified lake. Limnol Oceanogr 46: 392-409

Shanks AL (1983) Surface slicks associated with tidally forced

Editorial responsibility: Barry and Evelyn Sherr (Contributing Editors), Corvallis, Oregon, USA internal waves may transport pelagic larvae of benthic invertebrates and fishes shoreward. Mar Ecol Prog Ser 13: 311-315

Shanks AL (1995) Mechanisms of cross-shelf dispersal of larval invertebrates and fish. In: McEdward L (ed) Ecology of marine invertebrate larvae. CRC Press, Boca Raton, FL, p 323-368

Storlazzi CD, McManus MA, Figurski J (2003) Long-term high-frequency $\mathrm{ADCP}$ and temperature measurements along central California: insights into upwelling/relaxation and internal waves on the inner shelf. Contin Shelf Res 23:901-918

Strub PT, Allen JS, Huyer A, Smith RL (1987) Seasonal cycles of currents, temperatures, winds, and sea level over the northeast Pacific continental shelf: $35^{\circ} \mathrm{N}$ to $48^{\circ} \mathrm{N}$. J Geophys Res C 92:1507-1526

Wiebe PH, Holland WR (1968) Plankton patchiness: effects on repeated net tows. Limnol Oceanogr 13:315-321

Submitted: March 4, 2005; Accepted: April 5, 2005

Proofs received from author(s): September 27, 2005 